Cahiers d'études japonaises

\title{
La section consacrée aux poèmes japonais (waka) du Recueil des traditions de jadis et de maintenant (Kokon chomon-jū) de Tachibana no Narisue (1254)
}

\section{Franck Feurtey}

\section{(2) OpenEdition}

\section{Journals}

Édition électronique

URL : https://journals.openedition.org/cipango/1622

DOI : $10.4000 /$ cipango.1622

ISSN : 2260-7706

Éditeur

INALCO

Édition imprimée

Date de publication : 1 juin 2011

Pagination : 292-294

ISBN : 978-2-85831-195-8

ISSN : 1164-5857

Référence électronique

Franck Feurtey, "La section consacrée aux poèmes japonais (waka) du Recueil des traditions de jadis et de maintenant (Kokon chomon-jū) de Tachibana no Narisue (1254) », Cipango [En ligne], 18 | 2011, mis en ligne le 23 septembre 2013, consulté le 30 juin 2021. URL : http://journals.openedition.org/ cipango/1622 ; DOI : https://doi.org/10.4000/cipango.1622

Ce document a été généré automatiquement le 30 juin 2021.

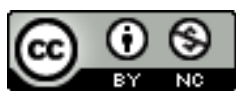

Cipango est mis à disposition selon les termes de la Licence Creative Commons Attribution - Pas d'Utilisation Commerciale 4.0 International. 


\title{
La section consacrée aux poèmes japonais (waka) du Recueil des traditions de jadis et de maintenant (Kokon chomon-jū) de Tachibana no Narisue (1254)
}

\author{
Franck Feurtey
}

\section{RÉFÉRENCE}

Franck FEURTEY, La section consacrée aux poèmes japonais (waka) du Recueil des traditions de jadis et de maintenant (Kokon chomon-jū) de Tachibana no Narisue (1254), mémoire de Master 2, sous la direction de Michel Vieillard-Baron, INALCO, 2012.

1 Le Kokon chomon-jū est un recueil d'anecdotes (setsuwa) compilé au milieu du XIII e siècle par un fonctionnaire de rang moyen de la cour impériale, Tachibana no Narisue. Cet ouvrage imposant (il ne rassemble pas moins de 700 anecdotes) présente une organisation systématique : les histoires se succèdent par ordre chronologique et sont classées en vingt sections thématiques, chacune de ces sections s'ouvrant sur une courte préface qui présente le thème dans son contexte historique ou mythique.

Notre étude a pour objet la section consacrée à la poésie japonaise (waka), qui occupe une place éminente dans le recueil, entre littérature et musique. Nous proposons une traduction annotée des 52 anecdotes de cette section, en laissant de côté les 36 anecdotes considérées comme des ajouts postérieurs à la compilation de l'ouvrage. Deux anecdotes en particulier consignent la relation détaillée de réunions poétiques, le Concours d'ceillets de l'impératrice douairière Senshi, qui s'est tenu en 986, et la Réunion célébrant le grand âge de fin de printemps à Shirakawa, organisée en 1172 par Fujiwara no Kiyosuke. Nous proposons une traduction des procès-verbaux (kiroku) de ces deux 
réunions, que Narisue a très vraisemblablement consultés, afin d'illustrer le travail de remise en forme auquel il s'est livré. En analysant la section consacrée au waka dans son ensemble, nous avons cherché à mettre en évidence les motivations qui auraient pu guider Narisue dans la sélection des anecdotes, notamment la vision de la poésie qu'il aurait souhaité présenter ou les enseignements qu'il aurait voulu transmettre.

Pour la plupart, les anecdotes étudiées ont trait à la correspondance poétique des hauts dignitaires, offrant ainsi de nombreux exemples des usages de la poésie comme mode de communication à la cour : des poèmes sont composés pour adresser ses vœux de longévité à l'empereur, pour évoquer le souvenir agréable d'un divertissement, pour exprimer sa gratitude, ses félicitations ou ses reproches. Le support sur lequel est calligraphié le poème (papier de qualité, tissu...), tout comme l'objet qui peut l'accompagner (en général un rameau fleuri), participe à l'élégance de l'ensemble. Bien souvent, Narisue consigne les poèmes échangés sans indication permettant de comprendre en quoi ils sont remarquables à ses yeux. On peut néanmoins supposer que c'est leur élégance, ou, plus encore, leur à-propos, qui ont leur ont valu d'être sélectionnés.

4 Si Narisue ne se livre à aucune critique d'ordre esthétique, il ajoute parfois de brèves remarques personnelles qui apportent un éclairage sur sa pensée. Elles témoignent notamment d'une foi bouddhique sincère: Narisue affirme ainsi à plusieurs reprises qu'il convient de placer la voie du Bouddha au-dessus de toutes les préoccupations du siècle, y compris les préoccupations artistiques. D'autre part, on perçoit au fil des anecdotes une admiration empreinte de nostalgie pour un passé où le prestige de l'empereur et de la noblesse n'était pas encore remis en cause par les clans guerriers. Pour Narisue, il était probablement important de montrer que la culture de la cour et ses traditions s'étaient transmises jusqu'à son époque, résistant aux troubles militaires et aux bouleversements politiques qui ont marqué l'entrée du pays dans le Moyen Âge. 